\title{
Outpatients revisited: subjective views and clinical decisions in the management of general surgical outpatients in south west England
}

\author{
Alex Faulkner, Allison Saltrese-Taylor, Jim O'Brien, Mark Williams, \\ Charles D Collins, Stephen Frankel
}

\begin{abstract}
Study objective - To assess the scope for reducing unnecessary outpatient reattendances, using as a benchmark an acute specialty at a site recognised to have an especially low ratio of repeat to new attendances.

Design - This was a survey of the reattendance workload at general surgery outpatient clinics over a three month period. Patient re-booking and discharge rates for different grades of staff; clinicians' perception of the ability of the GP to have managed the patient; perception of the value of individual re-attendances; reasons given for discharging/re-booking; and outcome of attendance for patients in relation to diagnostic category were determined.
\end{abstract}

Setting - General surgery outpatient clinics with re-attendance rates that were $50 \%$ below average, in Taunton and Somerset Hospital, a non-teaching district general hospital.

Patients - Altogether 454 patients who made 470 second or subsequent visits (reattendances) within the same episode of outpatient care.

Main results - Thirty eight percent (178/ 470) of visits were perceived as manageable by the GP, $45 \%(79,17 \%$ of total reattendances) of which were also thought to have been of marginal or little value. A substantial group of patients was being followed up largely for reasons of convention and traditional policy. Re-booking rates were higher among junior staff. Subjective views of the value of attendance at the hospital outpatient clinic and the ability of the GP to have seen the patient varied systematically between consultants and junior staff. Judgements varied to some extent according to the diagnostic group.

Conclusion - The numbers of patients being followed up equivocally at most general surgical outpatient departments will be $50 \%$ more on average than those in this benchmark department. A department seeing 2000 new patients per annum will have 3600 reattendances, $25.5 \%$ (918) of which may be avoidable on the basis of these results. A variety of approaches can be used to increase the proportion of patients seen appropriately by GPs. In some cases this might be achieved without the intensive commitment required to plan and develop shared care protocols or new formal discharge guidelines, but by encouraging GPs to manage some patients, increasing of hospital clinicians' access to knowledge of local general practices, and internal clinic review of 'routine' follow up policies as shown in this study. This type of review of outpatient practice can also help prioritise conditions likely to repay the effort of developing and implementing clinical management guidelines and local protocols.

\section{( $\mathcal{E}$ Epidemiol Community Health 1995;49:599-605)}

It is well known that repeat visits to outpatient clinics account for between $75 \%$ and $80 \%$ of all attendances recorded for this form of healthcare. ${ }^{1}$ Perennial doubts have been expressed within the medical profession over the value of repeated reattendances both to patient and clinician. The policy issues have been highlighted by the recent National Audit Office study, ${ }^{2}$ and subsequent review by the Parliamentary Committee of Public Accounts. ${ }^{3}$ Innovation in National Health Service organisation, notably general practitioner (GP) fundholding, is leading to an increased scrutiny of the legitimacy of outpatient re-bookings. In spite of the many assertions, however, there has been a relative lack of research or audit based evidence about causes, reasons, and possible justifications for the high levels of patients invited to return for follow up. This type of evidence is a prerequisite of attempts to design and progress toward viable alternatives to traditional outpatient reattendance or substitute care arrangements involving primary care.

No published study has examined these issues in the high volume specialty of general surgery, with its particular case mix and typical reasons for re-attendance. Diagnostic categories within specialties have generally not been taken into account in previous analysis of reasons for reattendance, although diagnosis has been identified as one predictor of the probability of discharge after the first attendance. ${ }^{4} \mathrm{~A}$ recent randomised trial of immediate discharge of selected surgical patients from a teaching hospital to general practice has concluded that primary care was of at least equal clinical effectiveness, and was less costly than traditional outpatient follow up. ${ }^{5}$ This enhances the need to base discussions of al- 
ternatives to traditional follow up on an improved understanding of the dynamics of the outpatient clinic.

A number of possible generic explanations have been put forward for high reattendance and rebooking rates in outpatient clinics on the basis of studies in other specialties. In particular, the influential role played by junior hospital doctors in needlessly inflating outpatient clinic reattendance rates is frequently asserted. There is evidence that they do recall patients in higher proportions than do their consultants, ${ }^{46-10}$ although some studies show no difference. ${ }^{11-13}$ This suggests that there is no simple explanation of observed reattendance rates and that other factors impinging upon decisions to offer repeat visits should receive more attention. The role of clinician status in relation to the management of patients in different diagnostic categories, and clinicians' opinions on alternative management require more in depth exploration.

This study describes the casemix of the outpatient workload in general surgical clinics, explores the relationship between case specific opinions about routine follow up as expressed by members of the surgical team and their actual management decisions, and analyses the stated reasons why clinicians re-book patients whom they believe could have been managed by their GP.

The study took place in general surgery outpatient clinics at a non-teaching district general hospital which had already introduced a policy of not offering routine follow up appointments to patients after uncomplicated surgery. ${ }^{14}$ This outpatient facility was staffed by consultants, registrars, and senior house officers, organised into four consultant "firms". The ratio of new to reattending patients at the time of the study was low $(1: 1 \cdot 2)$. This compares with a ratio of approximately $1: 1.8$ for general surgery across the South Western Health Region as a whole at the time of the study (KH09 returns). The data analysed here thus refer to a department in a high volume acute specialty, with an exceptionally low proportion of reattendances compared with the norm, in which only marginal scope for further planned reduction in reattendances might be expected. If however, there were shown to be substantial scope for further reduction, then the implications for the nature and volume of outpatient practice in general surgery would be very large indeed.

\section{Methods}

All follow up attendances at the general surgical outpatient clinics between July and September 1990 were surveyed. Examining doctors filled in a self completion questionnaire for each patient after the consultation, and further patient details were obtained from the case notes by one of the authors (A S-T). The questionnaire was developed in collaboration with the consultants in general surgery in the unit. It was piloted on 30 patients and appropriate changes were made to ensure face validity. All relevant clinical details for the sur- vey sample were cross checked against case notes. The records of non-attenders and patients for whom a questionnaire was not completed were checked to validate the completed questionnaire data; they were found to be representative of the broad diagnostic categories in the sample.

The questionnaire asked clinicians to indicate the main objective of each appointment, the actions taken, the type of continuation of care, and to rate, firstly, their perception of whether or not the patient's GP could have managed care and, secondly, their opinion of the overall necessity of the visit on a four point scale: "essential", "desirable but not essential", "of marginal benefit", or "not particularly useful". An open ended question then asked them to give in their own words a brief reason for the latter two judgements. During the study period, 559 follow up visits were planned. Forty seven patients $(8.4 \%)$ failed to attend; questionnaires were not completed for $42(7 \cdot 5 \%)$. Data were thus obtained for 470 second or subsequent visits within the same episode of care, by 454 separate patients. These 470 reattendances form the basis for the analysis presented here.

Analysis of numeric data was by frequency counts, cross tabulation, and descriptive summary statistics (using the Epi-Info software package). The association of qualitative variables (grade of staff and clinician opinion; clinician opinion and perceived necessity of outpatient visit) was analysed by means of the $\chi^{2}$ test with Yate's correction for two by two tables. This analysis was not extended to case mix, where aggregate of diagnostic groups would have been inappropriate. The reported textual data produced by the open ended questions were transcribed, classified by content, and hand counted by the first author (AF) and the classification decisions of the verbatim statements were checked by a second author (MW) to ensure consistency and reasonableness of interpretation.

\section{Results}

Three main clinical objectives accounted for $79 \cdot 2 \%$ of outpatient reattendances in this sample:

- Postoperative follow up;

- Returning for results/continuing investigations; and

- The monitoring or treatment of chronic or malignant disease. Details of all objectives are given in table 1.

The mean number of reattendances per patient was 3.54 , with a median of 2 . Sixteen patients had each made more than 14 reattendances (with a maximum of 41). Table 2 gives the median (and range) reattendances for each clinical objective. It also shows for each objective the three main outcomes of appointments, namely placement on a waiting list, discharge to the GP, and a further invitation to reattend. This illustrates, notably, that patients with the stated objective of returning for results or continuing investigations are placed on a waiting list in the highest pro- 
Table 1 Main clinical objectivres for reattending patients in general surgical outpatient clinic

\begin{tabular}{lrl}
\hline Main clinical objective & No & $(\%)$ \\
\hline Post-operative follow-up & 114 & $(24 \cdot 5)$ \\
Continuing investigations/returning for results & 103 & $(21 \cdot 9)$ \\
Monitoring or treatment of chronic/malignant condition & 154 & $(32 \cdot 8)$ \\
Treatment & 41 & $(8 \cdot 7)$ \\
Surgeon's interest & 29 & $(6 \cdot 2)$ \\
Patient's request & 11 & $(2 \cdot 3)$ \\
Miscellaneous & 18 & $(3 \cdot 8)$ \\
Total & 470 & $100 \cdot 0$ \\
\hline
\end{tabular}

portions, and that patients attending for monitoring or treatment of chronic/malignant conditions are discharged at a relatively low rate and have the highest proportion of rebooking.

One would expect the number of reattendances per patient to be related to the diagnosis, and this is the case. Diagnoses have been grouped according to ICD-9 codes. Table 3 illustrates the variation. Patients with the highest mean re-attendances at the clinic are those suffering from malignant neoplasms, colitis or enteritis, and vascular disease. Those with hernia, other bowel disease (motility disorders, ulceration or inflammatory changes related to oesophagus, stomach or duodenum, irritable colon or appendicitis), perianal conditions (haemorrhoids, pilonidal cyst, pruritis) and venous conditions are recalled, in general, on a more short term basis. Table 3 also shows the number of cases, analysed by diagnosis, for the extremes of reattendances and management, namely patients discharged on their first or second reattendance, and patients with between three and nine reattendances who have been asked to come again. It is clear that some conditions tend to be associated with long term attendance and that others have a much faster "turnaround". The table confirms that in the former category are, most clearly, malignant neoplasms and vascular disease, and to a lesser extent colitis/enteritis; and in the latter are the specified types of bowel disease, hernia, benign neoplasms, and perianal conditions.

\section{CLINICAL OPINIONS ON MANAGEMENT BY GP}

In the survey period, reattending patients were seen in the following proportions by each grade of staff: consultants $-22 \cdot 3 \%$ (105), registrars $-52 \cdot 6 \%$ (247), and senior house officers $25 \cdot 1 \%$ (118). Additionally, a consultant opinion was sought during one in four appointments with registrars and one in three with senior house officers.

Overall, clinicians judged that $38 \%$ (178) of their appointments could have been seen by the patient's GP. There was no notable difference between the mean number of reattendances by patients who could have been seen by their GPs and those who could not $(3.59 ; 3.61$ visits), suggesting that the frequency of a patient's attendance is not in itself a criterion of appropriateness of reattendance for clinicians. Of the patients stated to be returning for results of tests (not for continuing investigation), it was felt that the results could have gone direct to the GP, thus avoiding the appointment, in $33 \%(29 / 88)$ of the cases. Of the patients returning for treatment, none was deemed substitutable for GP care. Of the postoperative patients, it was considered that $47 \%$ (54/114) could have been seen by their GP instead, as could $40 \%(62 / 154)$ of those with malignant or chronic conditions.

These figures differed critically according to clinician status. Figure 1 indicates the mag-

Table 2 Reattendances and appointment outcomes for each clinical objective

\begin{tabular}{|c|c|c|c|c|c|c|}
\hline \multirow[t]{2}{*}{ Main clinical objective } & \multicolumn{2}{|c|}{ Reattendances } & \multicolumn{4}{|c|}{ Outcome of appointment } \\
\hline & $\begin{array}{l}\text { Median } \\
\text { (range) }\end{array}$ & No & $\begin{array}{l}\text { Waiting list } \\
(n=63) \\
\%\end{array}$ & $\begin{array}{l}\text { Discharged } \\
(n=167) \\
\%\end{array}$ & $\begin{array}{l}\text { re-booked } \\
(n=221) \\
\%\end{array}$ & $\begin{array}{l}\text { Other } \\
(n=19)^{*} \\
\%\end{array}$ \\
\hline $\begin{array}{l}\text { Postoperative follow up } \\
\text { Continuing investigations/returning for results } \\
\text { Monitoring or treatment of chronic/malignant } \\
\text { condition }\end{array}$ & $\begin{array}{l}2(1-30) \\
1(1-19) \\
3(1-41)\end{array}$ & $\begin{array}{l}114 \\
103 \\
154\end{array}$ & $\begin{array}{r}11 \cdot 4 \\
27 \cdot 2 \\
7 \cdot 8\end{array}$ & $\begin{array}{l}43 \cdot 0 \\
42 \cdot 7 \\
23 \cdot 4\end{array}$ & $\begin{array}{l}42 \cdot 1 \\
24 \cdot 3 \\
64 \cdot 9\end{array}$ & $\begin{array}{l}3.5 \\
5.8 \\
3.9\end{array}$ \\
\hline $\begin{array}{l}\text { Treatment } \\
\text { Surgeon's interest } \\
\text { Patient's request } \\
\text { Miscellaneous }\end{array}$ & $\begin{array}{l}1(1-11) \\
2(1-20) \\
2(1-25) \\
1(1-31) \\
2(1-41)\end{array}$ & $\begin{array}{r}41 \\
29 \\
11 \\
18 \\
470\end{array}$ & $\begin{array}{r}4 \cdot 9 \\
6 \cdot 9 \\
18 \cdot 2 \\
22 \cdot 2 \\
13 \cdot 4\end{array}$ & $\begin{array}{l}36 \cdot 6 \\
37 \cdot 9 \\
18 \cdot 2 \\
55 \cdot 6 \\
35 \cdot 5\end{array}$ & $\begin{array}{l}56 \cdot 1 \\
51 \cdot 7 \\
63 \cdot 6 \\
16 \cdot 7 \\
47 \cdot 0\end{array}$ & $\begin{array}{l}2 \cdot 4 \\
3 \cdot 5 \\
0 \cdot 0 \\
5 \cdot 5 \\
4 \cdot 0\end{array}$ \\
\hline
\end{tabular}

*Including 3 missing

Table 3 ICD9 outcomes of reattendance and total numbers of consultations within episodes of care in relation to diagnostic group

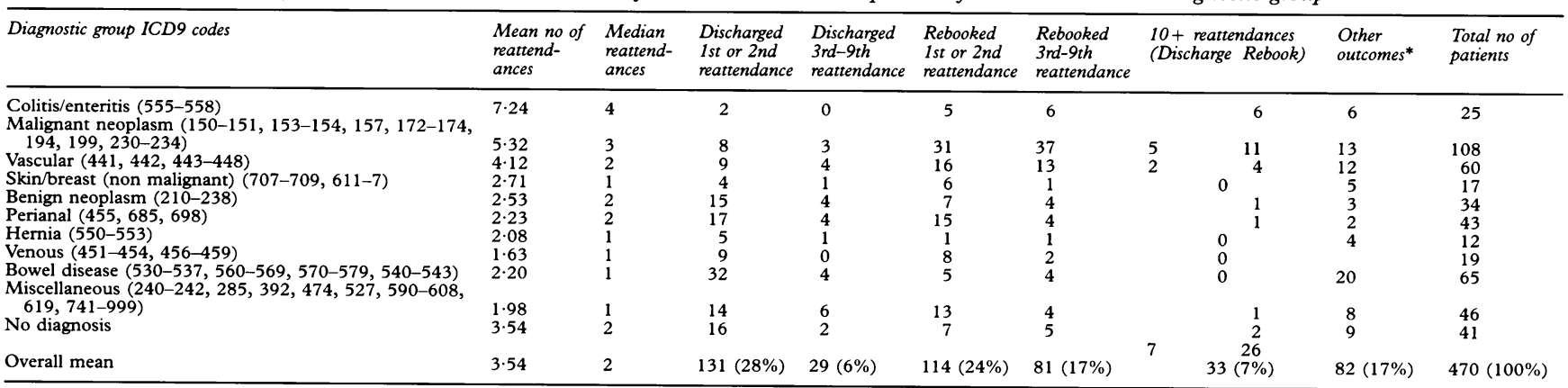

* Outcome values were missing for one each case of "vascular", "hernia", and "no diagnosis". 


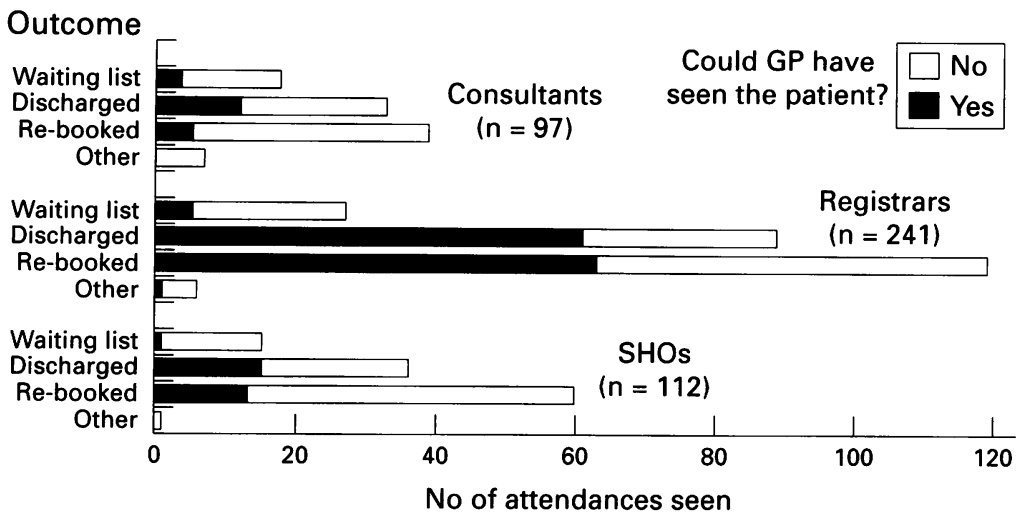

Figure 1 Outcome in relation to seniority of doctor and whether or not the patient could have been seen by a GP

\begin{tabular}{lcllll}
\hline & \multicolumn{2}{l}{ Outcome } & & & $\begin{array}{c}\text { Total (no } \\
\text { missing) }\end{array}$ \\
\cline { 2 - 5 } & Waiting list & Discharged & Re-booked & Other & \\
\hline $\begin{array}{l}\text { Consultants: } \\
\text { GP could have seen }\end{array}$ & 3 & 12 & 5 & 0 & \\
GP could not have seen & 15 & 21 & 34 & 7 & $97+8$ \\
$\begin{array}{l}\text { Registrars: } \\
\text { GP could have seen }\end{array}$ & 5 & 61 & 62 & 1 & \\
GP could not have seen & 22 & 28 & 57 & 5 & $241+6$ \\
$\begin{array}{l}\text { Senior house officer (SHO): } \\
\text { GP could have seen }\end{array}$ & 1 & 15 & 13 & 0 & \\
GP could not have seen & 14 & 21 & 47 & 1 & $112+6$ \\
\hline
\end{tabular}

$\chi^{2}$ : waiting list $=1 \cdot 12, \mathrm{p}=\mathrm{NS}(0 \cdot 5717)$; discharged $=13 \cdot 82, \mathrm{p}<0.001$;

re-booked $=27.56, \mathrm{p}<0.001$
There is, however, some suggestion that they saw a higher than average proportion of certain conditions, especially in the case of enteritis/ colitis $(44 \%, 11 / 25$, seen by consultants, although these cases amounted to less than $10 \%$ of consultants' workload in this study) and benign and malignant neoplasms (29\% (10/ 34 ) and $24 \%(26 / 108)$, respectively, seen by consultants). Many of these patients were long term reattenders. For patients reattending for their fifth time or more $(n=96)$, consultants' proportion increased to $30 \%$ and registrars reduced to $44 \%$. Within this group, proportions are the same for attendances with the explicitly stated purpose of monitoring or treatment of chronic or malignant conditions.

Of the 178 patients whom "the GP could have seen", 5\% (9) were nevertheless put onto the waiting list, $49 \%$ (88) were discharged, and $45 \%$ (80) were asked to reattend again. For those who were discharged, the average number of previous attendances was $2 \cdot 4$; for those asked to reattend it was 4.9 visits. In other words, patients with a longer history of visits were more likely to be asked to come again. For those who clinicians felt could have been seen by the GP but who were nevertheless re-booked (80), the mean interval to the new repeat visit was 32.4 weeks (median 26); for those rebooked and not deemed manageable by the GP the interval was only 20.6 weeks (median 12).

This study does not reproduce unequivocally the common finding that junior staff discharge patients at lower rates than consultants, although the trend is in this direction. Figure 1 shows the main outcomes of appointments for each clinician status separately, with the proportions for each outcome which were assessed as manageable by a GP. The ratio of those discharged compared with those asked to reattend varies somewhat between each clinician status (consultants $1: 1 \cdot 1$, registrars $1: 1 \cdot 3$, senior house officers $1: 1 \cdot 6$ ). On the other hand, of the patients discharged by registrars, those they assessed as capable of having been seen by the GP outnumber those whom the GP could not have seen by more than two to one $(68 \%, 61 / 89)$. Even among the appointments with registrars who were asked to re-attend, over half $(52 \%, 62 / 119)$ were nevertheless felt to have been manageable by the GP. This phenomenon was much less marked in the case of consultants and senior house officers. For consultants, of those discharged $36 \%(12 / 33)$ and of those reattending again only $13 \%(5 / 39)$ were felt to have been appropriate for the GP. For senior house officers the corresponding percentages were $42 \%(15 / 36)$ and $22 \%(13 / 60)$.

\section{OPINIONS OF VALUE OF ATTENDANCE}

In order to explain why a proportion of patients whom clinicians felt could be seen by their GP were nevertheless asked to reattend, the subjective views of the clinicians in the context of their working environment have been analysed. Figure 2 indicates the outcomes of consultation for patients assessed by the clinicians either as capable or not capable of having been 


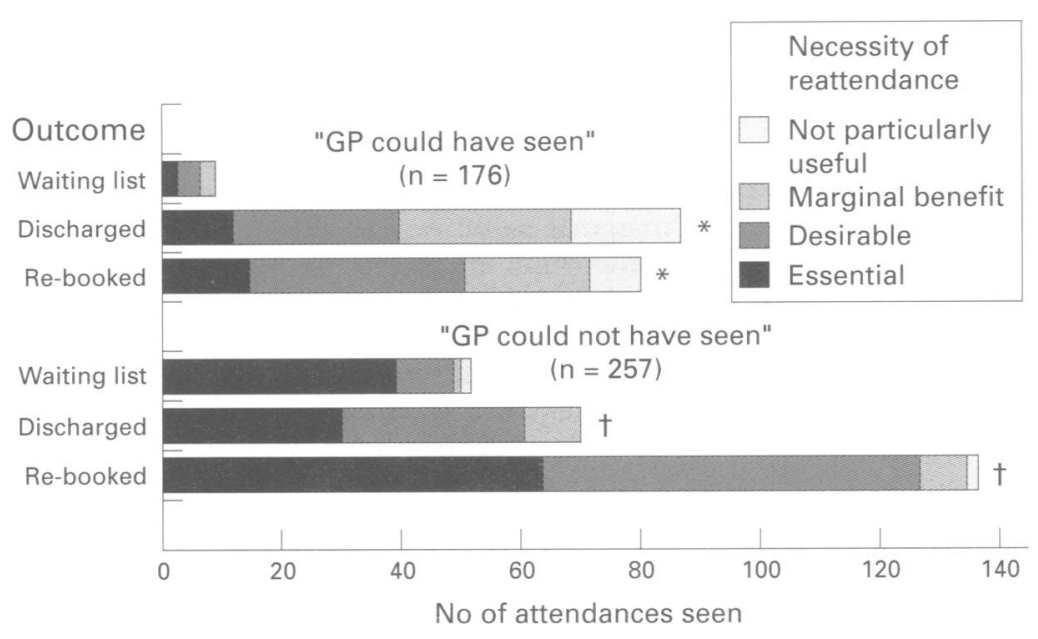

Figure 2 Outcome in relation to necessity of reattendance and whether or not the GP could have seen the patient

\begin{tabular}{lccccc}
\hline Outcome & Essential & Desirable & Marginal & $\begin{array}{l}\text { Not particularly } \\
\text { useful }\end{array}$ & $\begin{array}{l}\text { Total (no } \\
\text { missing) }\end{array}$ \\
\hline GP could have seen: & 3 & 4 & 2 & 0 & \\
$\begin{array}{l}\text { Waiting list } \\
\text { Discharged* }\end{array}$ & 12 & 28 & 29 & 18 & \\
$\begin{array}{l}\text { Re-booked* } \\
\text { Other }\end{array}$ & 14 & 37 & 21 & 8 & $176(2)$ \\
GP could not have seen: & 0 & 0 & 0 & 0 & \\
Waiting list & 40 & 9 & 1 & 1 & \\
Dischargedt & 31 & 30 & 9 & 0 & \\
Re-bookedt & 63 & 64 & 8 & 1 & \\
Other & 11 & 1 & 1 & 0 & \\
Total & & & & & $446(24)$ \\
\hline
\end{tabular}

$* \chi^{2}=4 \cdot 21, \mathrm{p}<0.05$ (essential/desirable $v$ marginal/not particularly useful)

$+\chi^{2}=1 \cdot 54, \mathrm{p}=\mathrm{NS}(0 \cdot 214)$; (essential/desirable $v$ marginal/not particularly useful)

seen by their GP, and shows, for each of the three key outcomes, their opinion of the value of the attendance.

Of those reattendances which the hospital clinicians felt could have been undertaken by the GP, the current hospital outpatient appointment was considered essential or desirable for $46 \%$ of the discharged patients' appointments (40/87) and $63 \cdot 8 \%$ of those invited to reattend $(51 / 80)$. In other words, the correlation between the perceived ability of the GP to have seen the patient and the clinician's rating of the necessity of the appointment was low. This varied systematically according to clinician status. Consultants felt a hospital outpatient appointment to be essential/desirable regardless of whether they felt that the general practitioner could have seen the patient or not: in $93 \%(90 / 97)$ of cases. On the other hand, of the 128 appointments which registrars felt appropriate for GP, they rated $44 \%(56)$ as of marginal or little value, and for senior house officers the corresponding percentage was $69 \%$ (20/29).

There was some variation in these judgements according to diagnostic group, as shown in table 4. Nearly one third (10/34) of the visits of cases of malignant neoplasm deemed manageable by the GP, but nevertheless asked to reattend again, were rated as of marginal value; conversely, none of this diagnostic group $(0 / 44)$, asked to reattend and not manageable by the GP, was regarded as of marginal value. Of those reattendances discharged and rated as not manageable by the GP, only nine overall were regarded as of marginal or little value; of those discharged and rated as GP-manageable, bowel disease stands out with $15 / 20$ attendances regarded as of marginal or little value (these 15 comprised diverticulitis (3), irritable colon (3), oesophagitis (3), cholelithiasis calculus of gall bladder without cholecystitis (1), acute pancreatitis (1), gall bladder - other cholecystitis (1), peptic ulcer unspecified (1), dyspepsia/other stomach disorder (1), and anal fissure (1)). None of the attendances of the six discharged patients deemed GP manageable with malignant neoplasm was regarded as necessary. On the other hand, most of the reattendances in this group for perianal conditions were regarded as desirable (8/11); the balance of perceived necessity for outpatient attendance among the other diagnostic groups was more even.

\section{REASONS FOR RE-BOOKING PATIENTS WHOM THE} GP COULD HAVE SEEN

The most critical group in this analysis is those who were asked to re-attend even though they were assessed as suitable for management by the GP. Of this $38 \%(178), 55 \%$ (98) were nevertheless regarded at least as desirable clinic attenders, and 51 of these were re-booked. Overall, 80 (45\%) patients whom the clinicians felt the GP could have seen were re-booked

Table 4 Perceived necessity of reattendance* for different diagnosis categories in relation to outcome of reattendance tand perceived ability of GP to have seen patient

\begin{tabular}{|c|c|c|c|c|c|c|c|c|c|}
\hline \multirow[t]{3}{*}{ Diagnostic group } & \multicolumn{4}{|c|}{ Outcome = discharge } & \multicolumn{4}{|c|}{ Outcome $=$ rebooked } & \multirow[t]{3}{*}{ Total } \\
\hline & \multicolumn{2}{|c|}{ GP could have seen } & \multicolumn{2}{|c|}{ GP could not have seen } & \multicolumn{2}{|c|}{ GP could have seen } & \multicolumn{2}{|c|}{ GP could not have seen } & \\
\hline & Necessary & Marginal & Necessary & Marginal & Necessary & Marginal & Necessary & Marginal & \\
\hline Colitis/enteritis & 0 & 1 & 0 & 1 & 1 & 0 & 13 & 3 & 19 \\
\hline Malignant neoplasm & 0 & 6 & 9 & 0 & 24 & 10 & 44 & 0 & 93 \\
\hline Vascular & 4 & 1 & 8 & 0 & 11 & 5 & 16 & 1 & 46 \\
\hline \multicolumn{10}{|l|}{ Skin/breast } \\
\hline $\begin{array}{l}\text { (non-malignant) } \\
\text { Benign neoplasm }\end{array}$ & 0 & 1 & 4 & 0 & 2 & 2 & 2 & 1 & 12 \\
\hline & 4 & 5 & 8 & 2 & 3 & 1 & 6 & 0 & 30 \\
\hline Perianal & 8 & 3 & 8 & 1 & 2 & 1 & 14 & 1 & 38 \\
\hline Hernia & 2 & 2 & 2 & 0 & 0 & 1 & 1 & 0 & 8 \\
\hline Venous & 4 & 2 & 3 & 0 & 2 & 1 & 7 & 0 & 19 \\
\hline Bowel disease & 5 & 15 & 11 & 4 & 0 & 1 & 11 & 4 & 43 \\
\hline Miscellaneous & 7 & 6 & 4 & 0 & 5 & 1 & 11 & 1 & 35 \\
\hline No diagnosis & 6 & 5 & 4 & 1 & 1 & 4 & 7 & 2 & 30 \\
\hline Total & 40 & 47 & 61 & 9 & 51 & 29 & 127 & 9 & 373 \\
\hline
\end{tabular}

* Perceived necessity has been summarised as follows: "essential" or "desirable but not essential" = "necessary", "of marginal value" or not particularly useful"= "Marginal" 
(figs 1 and 2). Analysis of the brief reasons given in this survey by clinicians for re-booking patients who could have been seen by the GP, reveals a mixture of practical considerations, routine, tradition, and policy underlying the observed rates. Actual reasons included: "lack of a request (either from the patient or the GP) for the GP to see the patient", "tradition to follow up breast cancer forever", "education for ourselves and to keep the morale of the patient up", "I didn't ask GP to", "we like in this instance to see the result of our work", "we like to follow up abdominal aortic aneurysms ourselves", "GP did see, but we wanted to also", "we like to follow up vascular cases for a while"," GP lack of sigmoidoscope", "follow up of graft patency", and other more vague reasons, such as "routine", "requested for close follow up", and "agreed to attend".

It is not possible to calculate absolutely clear proportions for the different categories of reason given, because interpretation of some of the verbatim written responses was open to doubt (for example "not requested" leaves it unclear whether the GP, patient, or clinician is being referred to). However, two types of reason stood out as the most common. They can be summarised as firstly: a lack of a request either from the GP or the clinician for the GP to manage the patient: at least $22 / 80$ responses (it is likely that some of those cases where no reason was given $(n=16)$ also fall into this category); secondly, routine or tradition (at least 15 cases, of whom all except one had diagnoses of malignancy, peripheral vascular disease, or aneurysm). It is worth noting also that although cumbersome discharge procedures have often been suggested as the reason for many unnecessarily re-booked patients, this reason was not offered in any case by the clinicians in this group.

\section{Discussion}

This study has implications for several important aspects of the phenomenon of reattendance at outpatient clinics. Firstly, a high performing, hospital outpatient service in general surgery was re-booking a significant proportion of patients for whom the appropriate mode of management was open to doubt. The low ratio of re-bookings to new attendances in this unit suggests that the proportion of these patients being recalled in most departments of general surgery will be some $50 \%$ larger than that reported in this study. The analysis was able to show particular diagnostic categories which would be candidates for review. A proportion of cases of bowel disease in particular, amongst the diagnostic categories, might have been reviewed as possible candidates for alternative management.

The difference in reattendance ratios between this and other departments, and the proportion of patients whose appropriate management was open to doubt and were potentially dischargeable, can be used to estimate the numbers of patients potentially dischargeable in an average department. Assuming a ratio of reattendances to new referral attendances of $1 \cdot 8: 1$ in a general surgery department seeing 2000 new referrals per annum, there would be 3600 reattendances. Multiplying the proportion found in this study to be both manageable by the GP and rated as of marginal value or less $(17 \% ; 79 / 470)$ by 1.5 (proportion of reattendances $50 \%$ higher in average departments) gives an estimate of 918 patient reattendances per annum $(1.5 \times 17 \%=$ $25.5 \% ; 25.5 \% \times 3600)$ the necessity of whose visit is likely to be equivocal amongst the clinicians themselves.

Secondly, the outpatient management of a small but not negligible proportion of patients seemed to be perpetuated simply for lack of either part at the primary/secondary interface making positive moves to take active responsibility for changing the care arrangements.

Thirdly, some patients who had had surgery for malignant or life threatening conditions were being followed up essentially as a matter of routine or tradition, as the consultants involved were well aware. These patients typically had long intervals between appointments - six months or more. Questions of alternative methods of follow up of patients with some of these conditions are now actively being considered in the United Kingdom.

Fourthly, the study shows the complex relationships between clinical case based opinions, clinical management practices, diagnostic categories, and the primary/secondary care interface in influencing the outcome of outpatient reattendance. Some $45 \%$ of the 178 patients rated by clinicians as manageable by the GP were nevertheless rebooked. This phenomenon has been reported previously be Leitch $e t$ al in respiratory medicine ${ }^{15}$ and Armstrong et al in gynaecology and general medicine. ${ }^{10}$ The present study has been able to show in addition that many of such attendances in general surgery are, in fact, regarded as desirable by clinicians, and it has been able to describe and analyse by diagnostic category the stated reasons given for retaining patients who in principle seem to be dischargeable. Account must, therefore, be taken of clinical opinions and reasons for retaining patients in addressing the question of substituting GP care for the clinic. Subjective assessments of the ability of GPs to manage patients may not be entirely consistent, but this study does indicate some broad regularities. Data such as these provide the basis for internal audit of clinical practices and policies as well as for informed discussion between clinicians, managers, and GPs. Involvement of GPs in research, development, or audit activities in this complex area will be of benefit in strengthening the basis upon which practical changes to patterns of care might be made. The extent of GPs' willingness to participate in innovative developments can be expected to depend in part upon their involvement in this type of review process, as well as upon workloads and experience in particular conditions.

Fifthly, the study provides evidence that registrars, in particular, place high value on a relatively small proportion of their attendances 
in comparison with consultants and senior house officers. Consultants exhibited extremely conservative, case-specific opinions. The reasons for this are unknown. It may be that consultants have experienced instances of mismanagement by GPs, or they may be out of touch with general practice. Alternatively this may reflect the commitment generated by professional specialisation, clinical authority and responsibility, and relatively long term local ties to the hospital. In some cases, registrars may have more confidence in general practice because of greater contact with GPs through mutual education programmes, although in many instances registrars are likely to see more "routine" cases because of case selection within the clinic. Lack of contact with GPs, and greater contact with consultants in clinic may also explain why senior house officers' perceptions were closer to those of the consultants than to the registrars. Given the uncertainties in these interpretations, there is a strong case for evaluating experimentally the effect upon the patient re-booking and discharge behaviour of junior hospital doctors of experience in general practice.

A number of practical approaches to improving the "appropriateness" of reattendance at outpatient clinics have been proposed. These include making discharge policy more explicit and organising training for juniors, ${ }^{10}$ improving the content of discharge letters to GPs especially for chronic conditions, ${ }^{15}$ increasing consultant review of casenotes with directive plans clipped to them, ${ }^{8}$ and the introduction of written guidelines for reattendance and discharge. ${ }^{16}$ All these types of measures have been reported as successful, and this study provides evidence to support extension of their application in general surgery.

Further practical measures and productive avenues for research and development are suggested on the basis of the analysis presented here. The study site provides a reference point for discussion between GPs and hospital clinicians of the potential scope for discharging patients to general practitioners, which could be applied to other general surgical departments. Specific measures to consider include: the feasibility of increasing practical contact between clinic and GPs through means such as educational activities; stimulating GPs' ability and willingness to request discharge of some patients; making better information about local general practices' facilities and training of GPs readily available to clinicians; and development of more explicit, agreed procedures for the management of patients with particular conditions. Given the typically long interval until the re-booked appointment, it might be possible to book selected repeat appointments on a "pending GP intervention" basis, and notify the GP with an invitation to consider assuming responsibility for the patient.

The clear disparity between the perceptions of consultants and registrars about the value of repeat appointments and GPs' ability to see patients suggests that there is potential for general surgical departments to consider locally the issues of both formal and informal clinical policies on reattendance and discharge, and for shared interval review of clinical criteria for "routine" repeat appointments between consultants and junior staff. More generally, it suggests that there is a strong case for comparative research to examine the specific factors which may account for the discharge and rebooking behaviour of junior staff in clinics with different (high versus low) reattendance and discharge performance.

In summary, clinicians in a general surgery outpatient department perceived that there was a large proportion of re-attending patients who could appropriately have been seen by the GP, but in many cases they were equivocal in judging the appropriate site of care and acting upon these judgments. There will doubtless always be come discrepancy between the aggregate of clinicians' opinions and their clinical actions. The method of review demonstrated in this study can help prioritise conditions which may be candidates for development of alternative care arrangements across the primary/secondary care interface. Indicators of possible levels of "inappropriateness" should be taken as the opportunity to review practices in a manner sensitive to the complexities of hospital outpatient practice as shown in this study.

We are grateful for the help and co-operation of the doctors who participated in this study, Mr S Jones, Mr I Ramus, and who participated in this study, Mr S Jones, Mr I Ramus, and Mr I Eyre-Brook, and that of the nursing, administrative and management staff in general surgery at Taunton $\&$ Somerset
Hospital. We thank an anonymous referee for comments on a Hospital. We thank an anonyr
previous version of the paper.

1 Department of Health. NHS hospital activity statistics for England 1979-1990/91. London: Government Statistica Service, 1992. Statistical Bulletin 2(1)92.

2 National Audit Office. NHS outpatient services. London HMSO, 1991.

3 Committee of Public Accounts. NHS outpatient services. London: HMSO, 1991.

4 Sullivan FM, Hoare T, Gilmour H. Outpatient-clinic referrals and their outcome. Brf Gen Pract 1992;42:111-115.

5 Du V Florey C, Yule B, Fogg A, Napier A, Orbell S, Cuschieri A. A randomised trial of immediate discharge of surgical patients to general practice. $\mathcal{F}$ Public Health of surgical patients to $\mathrm{g}$
Med $1994 ; 16(4): 455-64$.

6 Lester JP. Why not reclaim our outpatients from hospital outpatient clinics? $\mathcal{F} R$ Coll Gen Pract 1980;30:(213):230. 7 Grace JF, Armstrong D. Reasons for referral to hospital: extent of agreement between the perceptions of patients, general practitioners and consultants. Fam Pract 1987 4(3): 143-147.

8 Sparks D. A firm decision to save time. Health Services fournal 1988;98(5090):278.

9 Jolly U. Think of the client. Health Services fournal 1989; 99(5178):1434-5.

10 Armstrong D, Brown K, Tatford P, Armstrong P. Inappropriate re-attendances in out-patient departments. $\mathcal{F}$ Public Health Med 1992;14(2):173-6.

11 Marsh GN. Are follow-up consultations at medical outpatient clinics futile? $B M$ f $^{2} 1982 ; 284: 1176-7$.

12 Bosanquet N, Fordham R. Outpatient services - a case for treatment. Health Services fournal 1987;97(5070):550-1.

13 Cartwright A, Windsor J. Outpatients and their doctors: a study of patients, potential patients, general practitioners and hospital doctors. London: HMSO, 1992.

14 McCormack TT, Collier JA, Abel PD, Collins CD, Ritchie WN. Attitudes to follow-up after uncomplicated surgery hospital out-patients or general practitioner. Health Trends 1984;16:46-7.

15 Leitch AG, Parker S, Currie A, King T, McHardy GJ. Do chest physicians follow-up too many patients? Respir Med 1989;83:329-32.

16 Hall R, Roberts CJ, Coles GA et al. The impact of guidelines in clinical outpatient practice. $\mathcal{F} R$ Coll Physicians Lond 1988;22(4):244-7. 